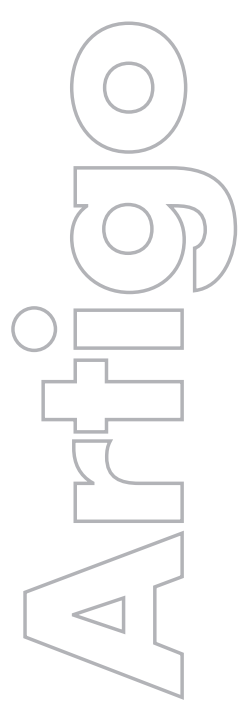

\section{revista}

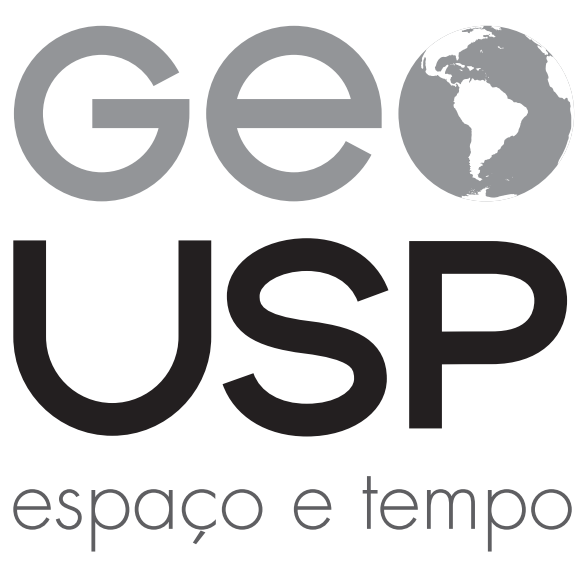

Volume $23 \cdot n^{\circ} 2$ (2019)

\section{Docklands: disputas intestinas na formação da paisagem urbana de Londres}

\section{André Lima de Alvarenga Universidade de Brasilia - Brasil}

p. $342-360$

Como citar este artigo:

ALVARENGA, A. L. Docklands: disputas intestinas na formação da paisagem urbana de Londres. Geousp - Espaço e Tempo (Online), v. 23, n. 2, p. 342-360, ago. 2019. ISSN 2179-0892.

Disponível em: https://www.revistas.usp.br/geousp/article/ view/157633. doi: https://doi.org/10.11606/issn.2179-0892. geousp.2019.157633.

\section{(C) $(1)(9$}

Este artigo está licenciado sob a Creative Commons Attribution 4.0 License. 


\title{
Docklands: disputas intestinas na formação da paisagem urbana de Londres
}

\begin{abstract}
Resumo
Ao longo de sua história, a área de Londres que hoje conhecemos como Docklands foi objeto de muitas disputas econômicas e políticas. Sua paisagem urbana constitui, e constituiu ao longo do tempo, o epifenômeno de tais contendas. Por um lado, empresas buscam espaços estratégicos e investem em tecnologia para se tornar mais produtivas e competitivas. Por outro, governos, instituições, partidos e associações políticas definem suas ações em prol de diferentes projetos de cidade, que, por sua vez, são estruturados em dois eixos ideológicos opostos: um mais liberalizante e outro mais socializante. Representadas pelos partidos trabalhista e conservador, ss duas linhas políticas se alternaram no poder. Nesse processo, ambos os grupos políticos foram obrigados a ceder quando confrontados com as consequências de suas ações ideologicamente orientadas.
\end{abstract}

Palavras-chave: Docklands. Requalificação urbana. Produção do espaço. Política urbana.

\section{Docklands: intestine disputes in the formation of London's urban landscape}

\begin{abstract}
Throughout its history the area of London now called Docklands has been the subject of many economic and political disputes. Its urban landscape constitutes, and has constituted over time, the epiphenomenon of such disputes. On the one hand, companies look for strategic spaces and invest in technology to become more productive and competitive. On the other hand, governments, institutions, parties and political associations define their actions in favor of different city projects, which in turn are based on two opposing ideological axes: economic liberalism, on the right, and labor communitarianism, on the left. The two political lines, represented by the Labor and Conservative parties, alternated in power. In this process, both political groups were forced to yield when confronted with the consequences of their own ideologically oriented actions.
\end{abstract}

Keywords: Docklands. Urban renovation. Production of space. Urban politics. 


\section{Docklands: disputas intestinas en la formación del paisaje urbano de Londres}

\section{Resumen}

A lo largo de su historia, el área de Londres que hoy conocemos como Docklands ha sido objeto de muchas disputas económicas y políticas. Su paisaje urbano constituye, y ha constituido a lo largo del tiempo, el epifenómeno de tales contiendas. Por un lado, las empresas buscan espacios estratégicos e invierten en tecnología para llegar a ser más productivas y competitivas. Por otro lado, gobiernos, instituciones, partidos y asociaciones políticas definen sus acciones en pro de diferentes proyectos de ciudad, que a su vez están estructurados en dos ejes ideológicos opuestos: uno más liberalizante y otro más socializante. Las dos líneas políticas, representadas por los partidos laborista y conservador, se alternaron en el poder. En ese proceso, ambos grupos políticos fueron obligados a ceder cuando se enfrentaban a las consecuencias de sus acciones ideológicamente orientadas.

Palabras-clave: Docklands. Recalificación urban. Producción del espacio. Política urbana.

\section{Introdução}

As reformas urbanísticas responsáveis pela requalificação e renovação dos espaços construídos originalmente para a finalidade portuária constituem um fenômeno característico do período que emerge com a Terceira Revolução Industrial. As renovações técnicas nos sistemas de transporte naval, com principal destaque para a conteinerização e a consequente concentração das atividades portuárias, tornou obsoletos muitos dos antigos portos industriais situados nas proximidades dos centros de negócios de grandes cidades. As áreas abandonadas foram em pouco tempo cobiçadas pelo capital imobiliário em face do crescimento do terceiro setor e a consequente demanda por escritórios e salas comerciais, mas também pela busca por produzir novos espaços residenciais próximos ao centro. Esse é o contexto que vai embalar a reforma portuária de Londres, a qual tratamos aqui.

$\bigcirc$ presente artigo constitui etapa de uma pesquisa que tem como objetivo analisar alguns dos mais importantes processos de requalificação ou renovação de antigas zonas portuárias ocorridos no mundo desde os anos 1980, notadamente Londres, Barcelona, Sidney e Rio de Janeiro, em busca de verificar como cada uma dessas cidades operou tais modificações em seu tecido urbano. A análise que aqui se faz é centrada apenas na zona portuária da cidade de Londres e tem seu foco nos arranjos políticos e institucionais que viabilizaram sua requalificação bem como nas suas implicações socioespaciais que engendraram insatisfações e conflitos que, por sua vez, acabaram por influenciar as políticas públicas. 


\section{A constituição das docas londrinas}

Detentora de um império naval desde o fim do século XVI, mais comprovadamente após a vitória sobre a Invencível Armada espanhola, em 1588, e a consequente assinatura do Tratado de Londres, em 1604 - momento a partir do qual começa a fixar suas colônias pelo globo -, a Inglaterra não tinha, até o fim do século XVIII, um sistema portuário organizado na capital. Havia apenas duas grandes docas: Brunswick Dock, no estaleiro Blackwall, cujo registro mais antigo data de 1661, e Howland Great Wet Dock, inaugurada em 1699, ambas destinadas à montagem e ao reparo de navios. Essas docas eram muito distantes da área urbana de então e não se destinavam às operações de carga e descarga de mercadorias.

Devido a seu calado, as embarcações mercantes que chegavam à urbe londrina não conseguiam atracar nos deques de madeira situados a beira-rio. Eram descarregadas e carregadas por meio de barcos a remo, como vemos na Figura 1. Também não havia armazéns: os bens eram estocados em dependências ou celeiros, e as vendas ocorriam nos píeres ou nas casas de mercadores (Edwards, 1992).

\section{Figura 1 - O rio Tâmisa e a Torre de Londres}

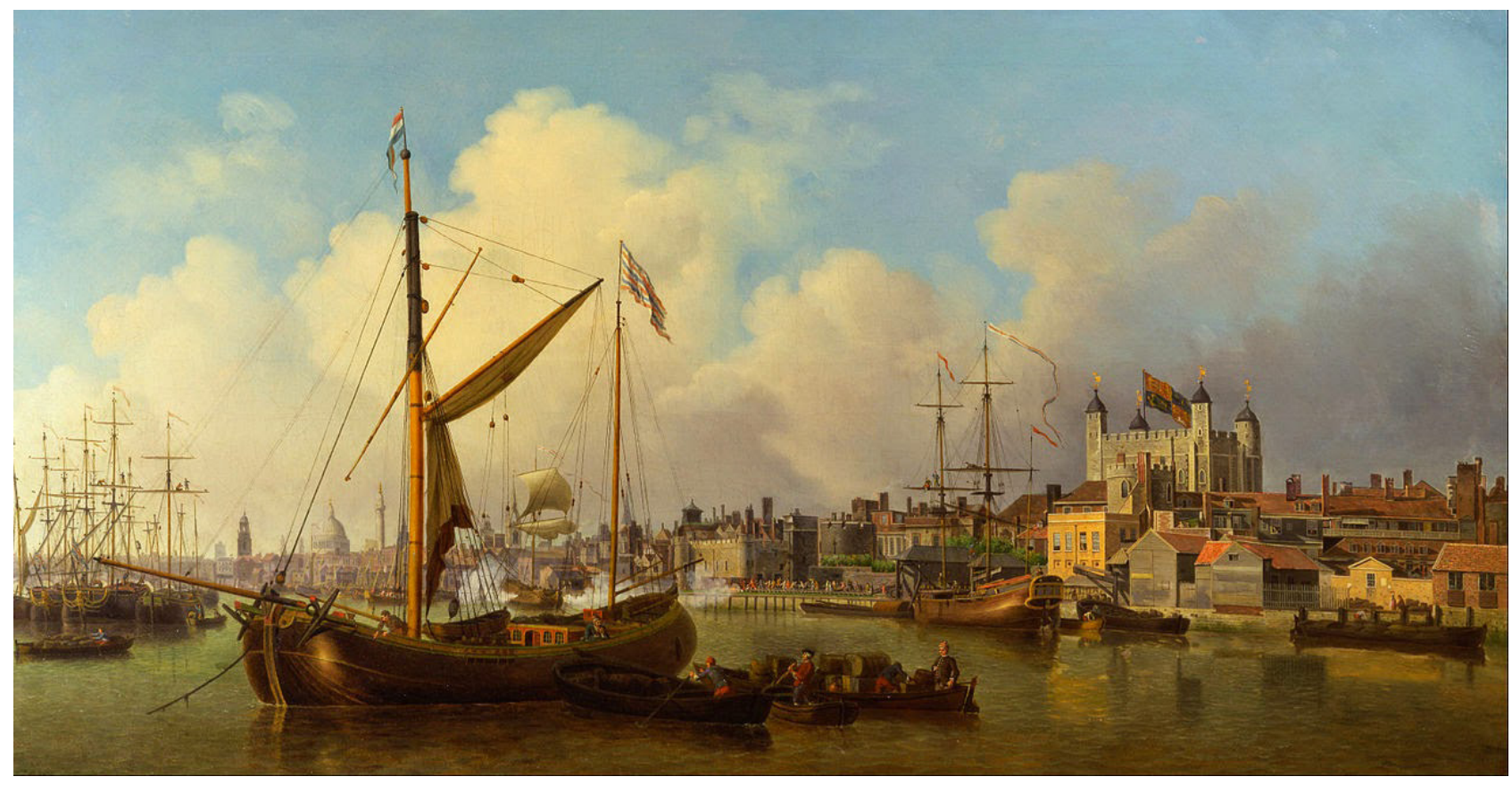

fonte: Scott (1771).

Ao longo do século XVIII, o volume de vendas do comércio londrino quadruplicou congestionando as atividades portuárias de então. Somente no início do século XIX, sob o efeito da revolução técnico-produtiva proporcionada pela máquina a vapor, docas modernas começaram a ser construídas no East End (Figuras $2^{1}$ e 3 ). Segundo os geógrafos Frédéric

\footnotetext{
O East End é uma área situada a leste da City of London. Até o século XIX, correspondia a uma vasta área rural situada a leste dos muros da cidade. A partir da instalação das docas londrinas, passou a ser uma zona industrial e de moradia das classes mais pobres e dos povos imigrantes. A partir da década de 1960, com a desindustrialização e a obsolescência do sistema portuário, cresceu o desemprego local, aumentando a crise social. A área vem sendo submetida a projetos de revitalização visando ao "balanceamento social", à valorização do solo e ao embelezamento da paisagem urbana.
} 
Monié e Soraia Vidal (2006), os grandes movimentos de reorganização dos espaços produtivos globais e das dinâmicas comerciais sempre envolveram mudanças na estrutura mundial dos portos.

Foi um Ato Parlamentar de 1799 que liberou a construção de docas por empresas privadas. Daí, em 1800, a empresa West India Merchant iniciou a construção das West India Docks e, em 1802, iniciaram-se as obras da London Docks. Na margem sul, o sistema Surrey Dock começou a ser construído em 1804, ampliando e renovando a antiga Howland Wet Dock. Sobre a antiga Brunswick Dock foi construída a East India Dock, em 1806 (PORT OF LONDON AUTHORITY, [s.d.]). Em poucos anos, Londres estava dotada de um vasto e moderno sistema portuário.

\section{Figura 2 - Carta da cidade de Londres, 1806 (a leste, o East End com os primeiros portos)}

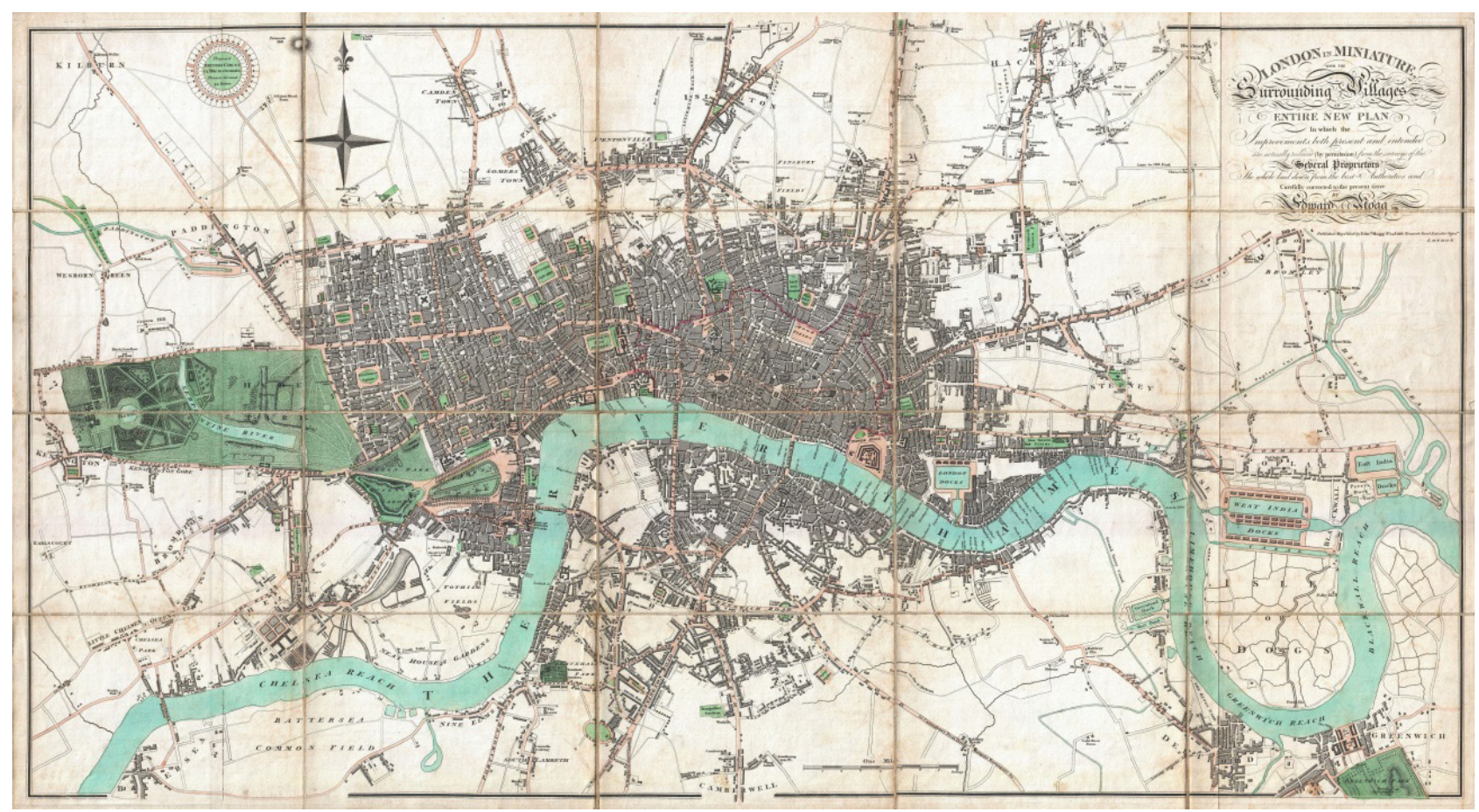

fonte: Mogg (1806).

\section{Figura 3 - Carta da área portuária de Londres, 1882}

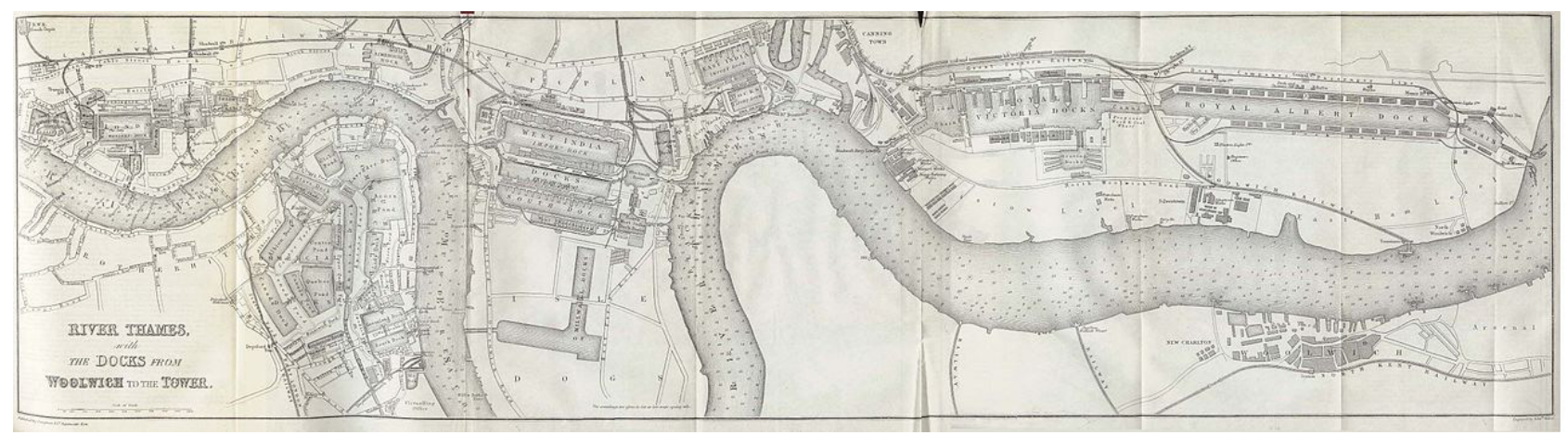

fonte: Weller (1884). 
No entanto, as evoluções técnicas dos navios mercantes e a concorrência entre as docas levaram a gradativa obsolescência dos primeiros portos londrinos e a necessidade de docas mais largas e profundas capazes de receber os "modernos" navios a vapor. Em 1828, é construída a St. Katharine Docks, ainda próxima ao centro. Para fazer frente a ela, em 1855, é construída a Victoria Dock em águas mais profundas, a jusante de Isle of Dogs. Essa doca é a primeira a ser diretamente conectada a uma linha de trem. Em 1868 foi construída a Millwall Dock, na Isle of Dogs, ampliando o sistema West India Dock (Edwards, 1992).

Na segunda metade do século, em face de adversidades financeiras, ocorreram fusões e aquisições das docas londrinas. As West e East India Docks foram amalgamadas. As London e St. Katharine Docks também se combinaram e compraram a Victoria Dock. Depois, este mesmo grupo construiu a Royal Albert Dock, considerada a melhor e mais larga bacia portuária do mundo até então, como extensão da agora renomeada Royal Victoria Dock. Assim, passou a receber os navios mais modernos e as melhores cargas. Em face disso a East and West India Docks Company construíram a Tilbury Docks ainda mais à jusante, em águas profundas, já fora de Londres, no condado de Essex, próximo à foz do rio Tâmisa.

No entanto, conforme avançou a técnica naval, quanto maiores eram os novos navios mais concentrador tendia a ser o sistema portuário. Dessa forma, a competição se acirrou e os dois grandes conglomerados portuários decidiram se unir, formando um cartel: o London and India Docks Joint Committee, que unia os esforços mútuos, embora com capital separado, na administração de todas as docas londrinas. Com a manutenção das dificuldades financeiras a renomeada London and India Docks Company enviou ao Parlamento um pedido de ajuda, que deu origem à formação de uma Comissão Real, que estudou o caso dos portos por dois anos e em 1902 propôs a criação de uma autoridade central.

Assim, em 1908, criou-se a Port of London Authority (PLA), com a função de dar mais racionalidade ao trabalho das docas e planejar a expansão do sistema portuário. A PLA se tornou a proprietária de todas as docas e armazéns de Londres, de modo que, a partir de um modelo liberal de concessão privada, a cidade constituiu um sistema portuário único e centralizador, e todas as docas passaram a ser controladas por um operador central: uma autarquia de controle estatal e fundos próprios, maior proprietária fundiária das margens do rio.

\section{Especialização, fragmentação e abandono}

Como explica Schubert (2008), o aparecimento dos portos modernos, no século XIX, foi acompanhado pela transformação das cidades. Destarte, com o desenvolvimento da zona portuária, processou-se em Londres um fenômeno que se repetiria em outras cidades que viveram a modernização de seus portos: a fragmentação porto/cidade. Antes da modernização, os atracadouros eram mercados base, além de centros comerciais para produtos de luxo internacionais. Contudo, "a relação íntima das cidades com o porto, seja como local de trabalho ou de moradia, gradualmente se dissolveu com a industrialização" (Schubert, 2008, p. 4).

Assim, a área construída de Londres cresceu e passou a sediar atividades e funções urbanas diversas às atividades portuária e administrativa - o que levou a uma crescente especialização/fragmentação de seu território. A City londrina tornou-se o centro de negócios por excelência, concentrando as atividades comerciais e de serviços - notadamente escritórios e 
sedes de grandes empresas comerciais, industriais e financeiras. $\bigcirc$ East End e a zona portuária, por sua vez, cresceram como uma vasta zona de trabalho portuário e industrial e de habitação imigrante e pobre.

Por outro lado, o porto também se especializou e passou a agregar em torno de si atividades de alguma forma implicadas na atividade portuária (Schubert, 2008). Os edifícios relativos a tais atividades, como acomodações, comércios, armazéns e escritórios, eram construídos nas imediações dos portos para facilitar a descarga direta de bens. Em Londres, a zona portuária aglomerava, além das docas, estaleiros e armazéns, diversas indústrias como cervejarias, fundições e moinhos, mas também alguns escritórios de companhias de seguros e outros serviços bancários.

Com a crescente expansão do sistema portuário as docas londrinas passaram a demandar uma enorme massa de homens sem exigência de escolaridade e especialização profissional, os quais, em grande parte, passaram a habitar a região. Por esse motivo, não só a área do porto, mas todo o East End londrino tornou-se uma grande área adensada, ocupada quase exclusivamente por população trabalhadora de baixa renda, com presença considerável de imigrantes vindos do campo e também de outros países, compondo um quadro multiétnico bastante plural e socialmente segregado.

Embora contígua ao centro, a zona portuária estava bastante apartada do resto da cidade, por diversos motivos. Em primeiro lugar, a região se destacava por sua paisagem e sua especialização funcional, mas havia outros motivos. $\bigcirc$ principal deles estava relacionado com a situação socioeconômica da população trabalhadora e residente. Enquanto a City concentrava os empregos bem remunerados dos grandes escritórios, a zona portuária concentrava grande contingente populacional pobre e imigrante.

O cenário de prostituição, alcoolismo e brigas, embora contrabalançado pela união dos trabalhadores na luta sindical, que frequentemente encontrava apoio de outros setores sociais (Lovell, 1969), produzia um imaginário bastante negativo da região para o restante da população citadina. A isso se somava a precariedade dos nodais de transporte locais. Beard (1979) explica que no final da década de 1970 as principais ruas e ferrovias evitavam a zona portuária. Por fim, altos muros margeavam a área do porto, dando à região a aparência de um verdadeiro enclave urbano (Hinsley; Malone, 1996).

A partir da década de 1920 as evoluções na técnica naval passaram a significar diminuição na oferta de trabalho portuário. Antigos navios mercantes foram trocados por grandes navios de ferro e o manuseio de bens foi mecanizado adotando-se o uso de guindastes (Schubert, 2008). A mecanização permitiu aumentar a escala das operações, mas por outro lado deixou sem trabalho um contingente enorme de pessoas e abalou a estrutura populacional local. Em 1901, o superpovoado East End, com sua população distribuída majoritariamente em três distritos - Bethnal Green, Poplar e Stepney, hoje absorvidos pelo novo distrito de Tower Hamlets - contava com cerca de 600 mil habitantes. Contudo, uma sucessão de eventos levaram ao paulatino abandono da região. Em 1931, com a manutenção do alto nível de desemprego local e o aparecimento de outras ofertas de trabalho mais ao norte ou mais ao leste, a população havia caído para 490 mil habitantes. Depois, foram os bombardeios nazistas que aceleraram o processo de abandono local. Não há registros estatísticos da população regional no imediato pós-guerra, mas em 1961 computou-se apenas 205 mil habitantes na área em tela (A VISION OF BRITAIN THROUGHTIME, [s.d.]). 
Por fim, a entrada em cena dos navios conteineiros, na década de 1960, acabou por tornar obsoleto todo o sistema portuário de Londres em 20 anos. $\bigcirc$ transporte internacional de cargas migrou para jusante ficando concentrado no porto de Tilbury, agora expandido. Por esse motivo, o número de vagas de emprego portuário passou de 30 mil na década de 1950 para apenas 2 mil em 1982 (Ward, 1986). Apenas entre 1969 e 1970, 13 mil vagas de emprego foram eliminadas no porto (Page, 1987). Esse processo de esvaziamento econômico fez com que a população da zona portuária fosse reduzida a 55 mil habitantes, em 1981.

Em paralelo, a Inglaterra passava por um período de rápida desindustrialização que levou grandes contingentes populacionais ao desemprego. E isso se deu mais acentuadamente no East End (Beard, 1979). A estagnação econômica local foi acompanhada da deterioração física das construções, constituindo um cenário de pobreza e abandono (Edwards, 1992).

\section{O rent gap e os dois projetos políticos para a reforma urbanística da região}

Contrariamente ao declínio da zona portuária, a cidade de Londres cresceu enormemente. Embora o processo de desindustrialização fosse constante e eliminasse milhares de empregos, a cidade vivenciava desde os anos 1970 um processo de crescimento avassalador do setor de finanças e serviços. Nesse período, a cidade viveu um rápido processo de suburbanização que fez crescer os distritos circunvizinhos à City. Isso resultou num vasto processo de conurbação, formando a Grande Londres. As amplas estradas de rodagem e a excelente maIha ferroviária permitiram que a população mais abastada se deslocasse para áreas ainda mais afastadas, onde podem levar um estilo de vida mais bucólico, enquanto tocam seus negócios no distrito central (Butler, 2007).

No início dos anos 1970, não apenas a zona portuária, mas toda a região periférica ao norte e ao leste da City encontravam-se relativamente desvalorizadas e ocupadas majoritariamente por famílias de baixa renda. No entanto, essa situação contrastava com o boom do mercado de escritórios vivido na área central, devido em grande parte à expansão dos setores financeiro e de serviços. Assim, a antiga zona portuária passou a representar uma reserva de valor capaz de abrigar a expansão da área mais valorizada da cidade: o centro de negócios.

Como explica Neil Smith (1979) em sua teoria do rent gap, o processo de suburbanização nas grandes cidades, cujos centros sediam grandes empresas, produz nos arredores do centro áreas de baixo valor relativo que passam a abrigar populações mais pobres, sem recursos para investir na manutenção ou no embelezamento dos imóveis. Com o tempo, a resultante degradação física e social da região acaba por intensificar o processo de desvalorização, e a região se desvaloriza a tal ponto que, face ao entorno bem mais valorizado (rent gap), ela volta a ser uma área cobiçada, com grande potencial de valorização mediante investimentos na recuperação e repaginação dos imóveis e do mobiliário urbano local. A resultante social desse processo consistiria na substituição da população pobre por uma população de classe média (gentrificação). Assim, muito embora a antiga zona portuária não consistisse numa área majoritariamente residencial, podemos dizer que seu terreno se encontra em situação análoga ao descrito na teoria de Smith.

Por esse motivo, Sir Edward Heath, primeiro-ministro britânico (1970-74) recusou o pedido do ministério dos transportes para injetar 50 milhões de libras para possibilitar a manutenção das atividades de porto até 1980 (Brownill; O'Hara, 2015), preferindo, no lugar, a reforma requalificadora da região. 


\section{O projeto de requalificação liberal do Conservative Party}

O primeiro passo no sentido da reforma portuária foi a constituição, em 1971, do Docklands Study Team. É a partir daí que surge o termo docklands para designar essa área de 2.200 ha que se estende por $13 \mathrm{~km}$ para jusante, indo de Tower Bridge até Barking Creek, na margem norte, e até a Thames Barrier, na margem sul (Figura 4). Este grupo de estudos produziu 18 diferentes cenários para a região, dos quais um foi escolhido e desenvolvido como modelo para as transformações a serem empreendidas (Brownill; O'Hara, 2015). O projeto vitorioso, elaborado pela empresa de urbanismo Travers Morgan, chamado City New Town, foi apresentado em 1973 e visava criar 60.000 novos empregos do setor de serviços e cerca de 1.000 empregos industriais. Também estimava aumentar a população residente em 142.000 habitantes, melhorando a "balança social" local com a meta de atingir uma divisão 50/50 entre habitações privadas e públicas (Edwards, 1992).

\section{Figura 4 - Delimitação das Docklands}

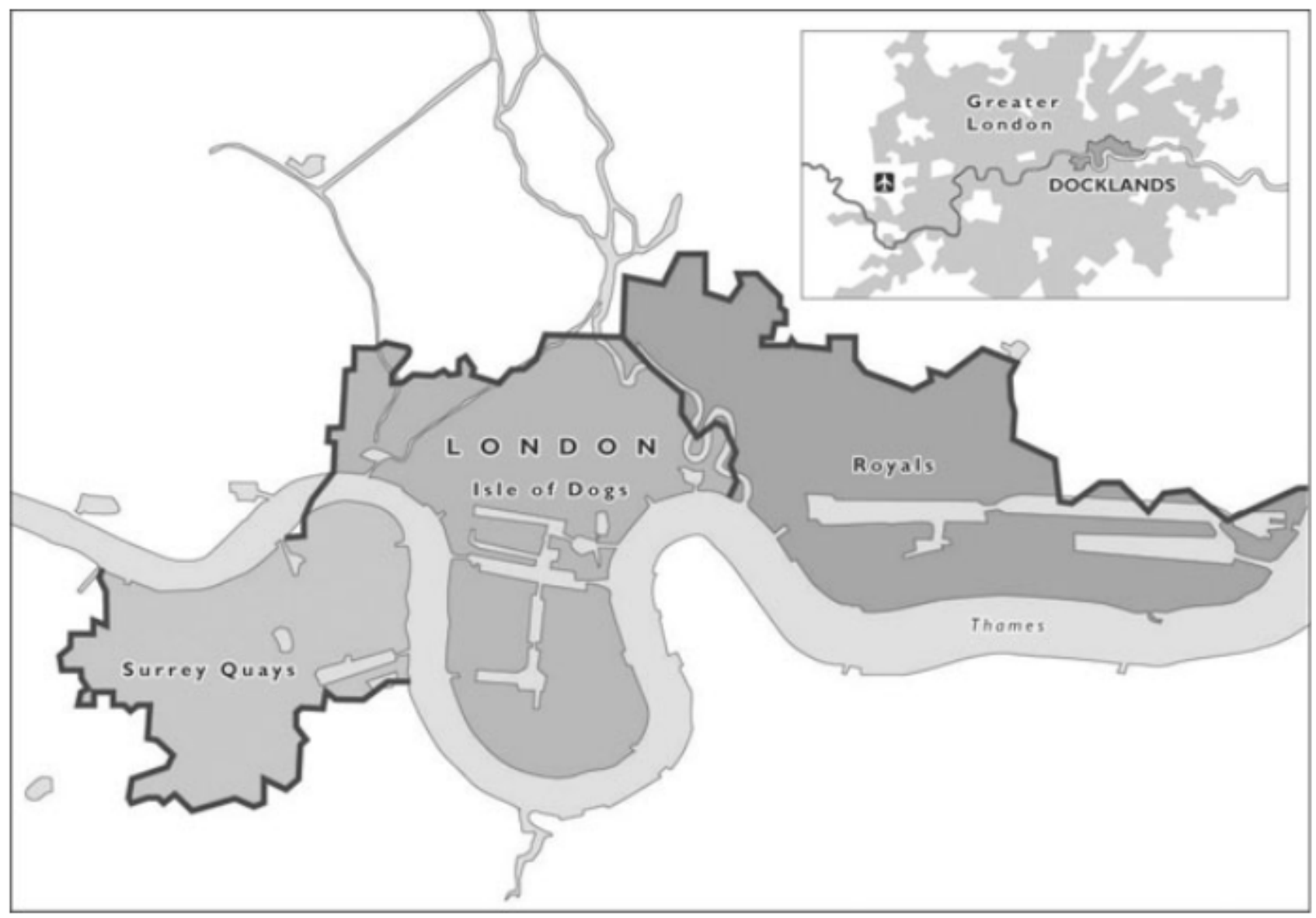

fonte: Butler (2007).

No entanto, o processo de transformação urbana da região não ocorreu sem disputas. Os principais embates se deveram à natureza das composições partidárias inglesas, de um lado, e da estruturação do poder dos conselhos comunitários locais, de outro. Enquanto os trabalhistas eram voltados a interesses da classe trabalhadora e de base local, os conservadores estavam ligados aos interesses empresariais. 
Assim, já no primeiro momento, ainda na fase de projeto, houve forte oposição de grupos locais liderados pelo Partido Trabalhista, pelo fato de o plano não ter consultado os Conselhos locais e por não ter como foco principal nem as demandas dos residentes remanescentes nem a criação massiva de emprego industrial. Para se contrapor ao projeto de 1973, foi prontamente criado o Joint Docklands Action Group, para unificar as diversas visões dos grupos locais (Brownill; O’Hara, 2015, p. 543).

\section{O projeto de requalificação de base local do Workers Party}

Em 1974, com a chegada do governo trabalhista de James Callaghan, o projeto City New Town foi descontinuado e rotulado pejorativamente de "uma série de sonhos". A nova administração, mais sensível à demanda local, defendia a ênfase na habitação popular, no emprego industrial e na manutenção operacional das docas (Brownill; O' Hara, 2015). Havia pressão política da comunidade local nesse sentido, mais interessada numa reabilitação da área, ou seja, numa recuperação local visando salvaguardar o restauro arquitetônico e do tecido social, do que em grandes projetos de requalificação ou renovação (Duarte, 2005).

Para encaminhar as reformas necessárias, Callaghan criou, já em janeiro de 1974, o Docklands Joint Committee (DJC): um comitê composto por profissionais nomeados pelo governo central em conjunto com os representantes dos cinco distritos portuários mais a City, além do Conselho da Grande Londres e indivíduos das comunidades locais (Church, 1990). Após dois anos de trabalho, o DJC lançou o Plano Estratégico das Docklands (PED) como uma alternativa radical ao projeto do escritório Travers Morgan. Esse plano foi, em grande medida, uma resposta às necessidades locais, mas também refletia preocupações com o papel e a natureza do planejamento, o crescimento da política comunitária e a mobilização de grupos de ação locais. Segundo Edwards (1992), recomendou-se no PED que as zonas portuárias fossem destinadas à habitação e ao emprego da população local, dando maior ênfase à manutenção e à atração de indústrias do que ao setor de serviços. $O$ PED também indicava a construção de 23 mil novas casas, com uma mistura de 50\% do próprio governo, com aluguel subsidiado para uso popular, $30 \%$ de propriedade compartilhada e $20 \%$ privadas, a serem ocupadas pelos próprios donos. Também estavam previstas melhorias no transporte local, com a construção de uma linha leste-oeste de metrô (Brownill; O’Hara, 2015).

Mas, apesar da defesa pública do projeto "popular" para as docas, o governo trabalhista encontrou dificuldades jurídicas e financeiras para realizá-lo. Assim, não alocou recursos públicos suficientes para comprar as terras da antiga zona portuária, em parte de propriedade da Autoridade do Porto de Londres (Church, 1990) e em parte de proprietários privados. Como explica Page (1987), um dos maiores motivos para o fraco suporte financeiro do PED era a disputa entre os distritos para receber reformas urbanas de grande prestígio. Edwards (1992) explica que os foros locais populares e, principalmente, o Fórum das Docas, que reunia todos os demais, acabaram por se tornar altamente burocratizados e empenhados em discussões intermináveis, sendo muito difícil, demorado e custoso chegar a algum acordo.

Como o financiamento público não veio, o DJC passou a buscar o capital privado (Barnes; Colenutt; Malone, 1996). No entanto, essa fonte de investimentos tinha sua própria lógica de operação e suas próprias demandas para a região, que contrastavam com as demandas 
populares. Assim, novidades foram inseridas no plano, como a implantação de um trade mart em Surrey Docks. Por outro lado, demandas populares fundamentais, como habitação popular, não foram conseguidas. Por sua vez, o setor privado demandava um regime mais centralizado e eficiente, em oposição ao Fórum das Docas. Portanto, apesar de toda a participação popular e do apoio governamental, a reforma que se implementava não era propriamente aquela defendida por meio de consulta popular e contida no Plano Estratégico, mas uma mais afinada com os interesses dos investidores privados.

Contudo, apesar da dificuldade financeira em adquirir e aglutinar terras para colocar em prática o plano urbanístico, o DJC iniciou diversos trabalhos de drenagem e aterramentos de algumas bacias portuárias, como foi o caso da London Docks, parte de Surrey Docks, East India Docks e parte de Royal Docks. Outras áreas, como a outra parte de Surrey Docks e a bacia de Shadwell converteram-se em áreas destinadas à recreação (Beard, 1979). As docas West India, Millwall e Royal Docks se mantiveram operacionais.

No final do governo Callaghan, com algum esforço financeiro, 240 casas haviam sido construídas e 1.100 estavam em construção. No entanto, durante seu mandato a operação portuária londrina continuou a se esvaziar. Em 1981, as Docklands viviam seu momento mais crítico de declínio econômico (Church, 1990), com 40\% de sua área abandonada ou vacante. Portanto, apesar de seu maior apoio e participação popular, a gestão trabalhista não conseguiu avançar no projeto pretendido, e o porto continuou a se esvaziar até fechar completamente em 1980.

\section{A eleição de Margaret Thatcher e a vitória do projeto liberal}

Com a eleição de Margaret Thatcher, em 1979, e a ascensão da nova onda liberalizante, nova reviravolta: o DJC foi extinto e o PED, de 1976, abandonado (Barnes; Colenutt; Malone, 1996). Com o intuito de promover a renovação da antiga zona portuária e de outros cinco distritos da zona pericentral de Londres, também em situação de rent gap, o novo governo criou as Urban Development Corporations (UDC). A elas foram dados poderes para a criação de um ambiente atrativo para o investimento, mas também para a promoção do desenvolvimento da indústria, do comércio, da habitação e das instalações sociais, com vistas a encorajar sua ocupação (Edwards, 1992).

A UDC mais importante era a London Docklands Development Corporation (LDDC), criada em 1981 e dedicada à antiga zona portuária. A esta nova instituição foi dado o comando de toda a zona portuária, agindo como "um grande centro de controle erguido sobre os governos locais" (Barnes; Colenutt; Malone, 1996, p. 24). A LDDC constituía uma autoridade central, não eleita diretamente pela população, com poderes para promover, "com agilidade e eficiência", a requalificação da região (Church, 1990, p. 290). Seguindo a doutrina econômica liberal, à LDDC foram dados recursos financeiros para reunir terras e depois vendê-las a empreendedores imobiliários. $\bigcirc$ objetivo dessa UDC era criar incentivos para redinamizar a região: contra um cenário de despovoamento, ela visava gerar um novo senso de propósito para as Docklands por meio do crescimento empresarial (Ward, 1986).

Retirou-se a prioridade do critério social no processo de tomada de decisões e operou-se um regime de planejamento "flexível" (Ward, 1986), amigável às construtoras. A LDDC teve recursos para finalizar as drenagens e aterramentos, fazer novas ruas, demolir construções 
antigas, construir um Veículo Leve sobre Trilhos (VLT), o London Docklands Rail (LDR), e investir pesadamente em publicidade. No entanto, a palavra planejamento era malvista, tida como parte de um vocabulário ideológico cuja doutrina levava ao inchaço do Estado e à estagnação da economia. Isso se deu de tal forma que a reconstrução da antiga zona portuária representava um verdadeiro laboratório em que a doutrina econômica neoliberal seria aplicada ao planejamento urbano.

\section{A incorporação urbana sem planejamento estatal}

Envolta numa retórica liberal, a requalificação visava tornar a zona portuária londrina em uma área de oportunidades e pouco entrave para os negócios. O grau de empenho do governo britânico e da Primeira Ministra indicava que o desenvolvimento da região representava uma grande vitrine para a doutrina econômica que se defendia. Para o Conservative Party o crescimento do novo Centro de Negócios significava a própria concretização do Thatcherismo. "As Docklands simbolizavam a teoria de que a riqueza gerada numa 'economia livre' poderia se espraiar por tudo para engendrar melhorias físicas e sociais nos bairros pericentrais" (Hinsley; Malone, 1996, p. 38). Nesse sentido a retórica liberal passou a fazer parte da própria campanha de marketing governamental que buscava dar a região uma nova imagem capaz de engendrar mensagens de riqueza e de futuro promissor.

Dentro desse espírito a nova doutrina buscava se afastar de todo tipo de ação que pudesse ser associada ao conceito de intervenção do Estado. A ideia de planejamento estatal foi, portanto, combatida em prol da compreensão de que a livre iniciativa poderia dar conta da requalificação. Nesse sentido, uma das primeiras decisões do quadro de controle da LDDC foi com relação à adoção de um plano de desenvolvimento flexível (Ward, 1986).

Foi dentro desta perspectiva que o governo transformou uma área de 192 ha. em torno da antiga West India Docks em uma Zona Empresarial (ZE) por um prazo de dez anos (Edwards, 1992). As ZE consistiam em um estatuto jurídico que tornava livre de taxações, impostos e outras regulações burocráticas áreas selecionadas do território, por um dado período de tempo. Esse ato possibilitou a construção de Canary Wharf, um megaempreendimento imobiliário com estrutura classe A para o estabelecimento de empresas do setor financeiro e afins, com o intuito de fundar nas Docklands o terceiro centro de negócios de Londres, depois da City e de Westminster. A chegada desse novo empreendimento trouxe para o concreto a nova imagem que o marketing urbano buscava dar à região e por sua vez, acabou atraindo outros grandes empreendimentos para a área renovada.

Assim, impulsionadas pelo crescimento do setor de finanças e serviços e pelo rent gap local e promovidas por incentivos fiscais e pela retirada de constrangimentos legais, as Docklands vivenciaram, logo nos primeiros anos de operação da LDDC, um boom da construção e do design urbano.

Contudo, apesar de a reforma urbana da zona portuária de Londres ser considerada o programa de requalificação portuária com maior protagonismo do mercado em todo o mundo, sendo inclusive qualificado por autores como Church (1990) como um urbanismo sem planejamento, Edwards (1992) explica que a participação estatal nem por isso foi pequena. Segundo o autor, foi adotado ali o que chama de planejamento mercadológico, do qual podem 
ser identificadas três modalidades: o planejamento de tendência, "que dá espaço livre para o desenvolvedor e limita o planejador urbano estatal ao trabalho de "lubrificar' o maquinário de investimentos públicos para a vantagem do desenvolvedor privado" (Edwards, 1992, p. 26); o planejamento de alavancagem, "em que o dinheiro público é dirigido a atrair o investimento privado" (Edwards, 1992, p. 26); e o planejamento de administração privada, no qual uma empresa ou consórcio fica responsável pelo planejamento, execução e manutenção de uma área urbana. As três modalidades se realizaram nas Docklands londrinas.

De fato, o empenho governamental e o investimento estatal na reforma urbana não foram pequenos. Durante os dois mandatos do governo Thatcher a LDDC investiu um bilhão de libras somente na Isle of Dogs. Ward (1986) cita três importantes investimentos de iniciativa estatal que ajudaram a mudar rapidamente a imagem de abandono e isolamento da região tornando-a atrativa: o Docklands Light Railway, o London City Airport (LCA) e o Centro Nacional de Telecomunicações. A partir de 1984, a região passou a abrigar também o Teleporto de Londres, tornando a região particularmente atrativa para grandes organizações como bancos internacionais. Assim, houve um importante empenho em levar para a região construções emblemáticas capazes de alterar a imagem pública local e atrair investimentos por meio da publicidade (Brownill, 1999).

\section{Figura 5 - Canary Wharf}

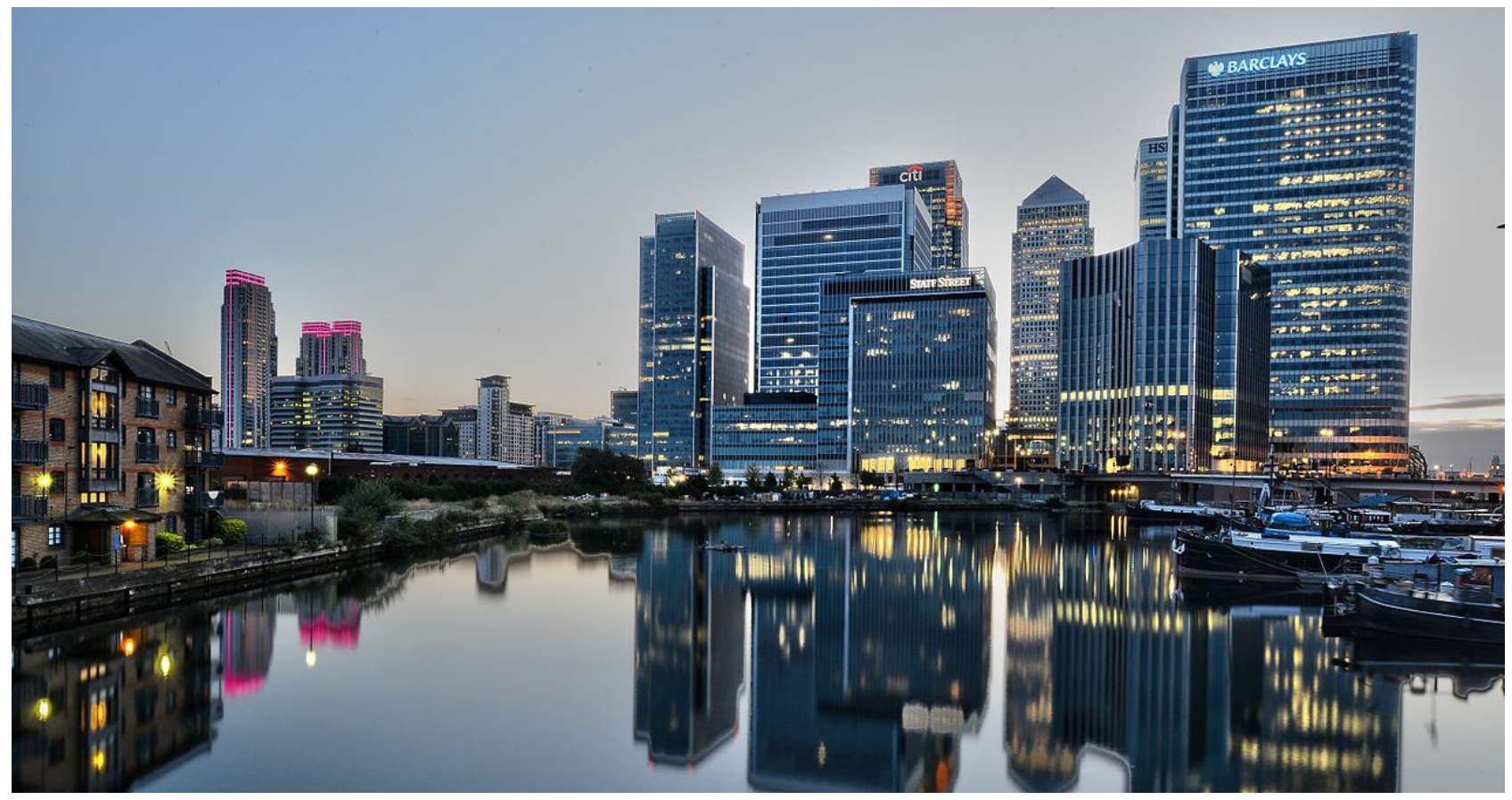

fonte: Yousaf (2014).

No campo do que Edwards (1992) chama de planejamento de administração privada, o melhor exemplo a ser observado é a própria Canary Wharf (Figura 5). O projeto, desenvolvido pelo empreendedor imobiliário norte-americano G. Ware Travelstead e construído pela empresa canadense Olympia E York, a partir de 1988, consistiu na aquisição privada de toda a área das West India Docks e seu entorno próximo (totalizando 1,4 km²) por uma única empresa e a poste- 
rior construção de vinte e seis edifícios comerciais, sendo cinco arranha céus. Esse megaempreendimento é majoritariamente composto por escritórios, contendo também 200 lojas, restaurantes, cafés, academias de ginástica, trazendo para a região mais de 40.000 novos empregos no setor de serviços (Hinsley; Malone, 1996). Em 1990, construiu-se o primeiro arranha-céu, que foi por 20 anos o edifício mais alto do mundo (Kollewe, 2015). A partir de então, Canary Wharf se tornou um paradigma da arquitetura do fim do século XX. "A combinação de torres modernas, uma base neoeduardiana e uma paisagem beaux-arts pode ser visto como bizarro, mas expressa a realidade da commoditificação e a aliança da estética com a renda" (Hinsley; Malone, 1996, p. 55).

Em dez anos a antiga zona portuária passou a prover 15 por cento do espaço de escritórios da cidade, atraindo cerca de 100.000 empregos somente na Isle of Dogs. Com toda a transformação e o marketing urbano envolvidos na requalificação urbana, os preços da terra cresceram quatro vezes no lugar, ainda nos primeiros cinco anos da década de 1980 (Barnes; Colenutt; Malone, 1996). Até 1989 a regeneração e o investimento do setor privado tinham atingido suas metas iniciais. Church (1990) informa que, nesse período, 0,8 milhão de metros quadrados de espaço industrial e comercial já tinha sido construído (a maior parte da ZE da Isle of Dogs) e 11.000 novas casas estavam prontas para venda a proprietários individuais. $\bigcirc$ investimento privado de $£ 6,85$ bilhões em diversos empreendimentos imobiliários mudou rapidamente a paisagem das Docklands (Church, 1990). Em pouco tempo, novos empreendimentos voltados ao setor financeiro foram iniciados nas Royal Docks, a nova fronteira de desenvolvimento da antiga zona portuária.

No entanto, após o boom da década de 1980, a região viveu um longo período de estagnação. A crise no mercado imobiliário britânico (1987-1988) levou a uma queda nos preços das propriedades das Dockalands de cerca de 43\% entre 1988 e 1994 - a maior desvalorização de toda Londres. A região foi a mais afetada da cidade devido a superposição da crise imobiliária com a crise local de mobilidade.

\section{Crises, críticas e adaptações: o retorno da intervenção estatal}

Muitas críticas foram feitas a atuação da LDDC no processo de requalificação das Docklands, destacamos aqui a falta de relacionamento com as instituições locais de representação popular e a opção ideológica de insistir no desenvolvimento sem planejamento estatal. Deixando-se a tarefa de desenhar a produção do novo East End para "a mão invisível do mercado", o espaço resultante materializou as contradições inerentes ao próprio processo de apropriação da região pelo capital imobiliário. Como resultado, a antiga zona portuária vivenciou uma grave crise de transportes que acabou por levar a uma estagnação no desenvolvimento. Vejamos como isso se deu.

Nos primeiros anos de requalificação, o principal investimento em mobilidade consistia em instalar o DLR ligando Tower Hill e Stratford à Island Gardens, na Isle of Dogs, ao LCA, nas Royal Docks. Inaugurado em 1986, esse VLT dava conta de 8.000 passageiros por hora nos horários de pico (Church, 1990). Outros investimentos se destinaram a construção de novos arruamentos, instalação de linhas de ônibus e micro-ônibus, transporte fluvial, por meio da empresa Thamesline, que começou a operar em 1988 e, por fim, viagens aéreas também se tornaram disponíveis localmente com a construção do LCA. 
Mas, apesar da pluralidade de opções a rede de transportes não conseguia dar conta dos 24.000 passageiros por hora na Isle of Dogs, em 1989. Nesse momento, as ruas na península encontravam-se bastante congestionadas com apenas 400 carros em circulação por hora: as estimativas indicavam quatro vezes mais carros para 1991, com a conclusão de novos edifícios (Church, 1990). Edwards (1992) relata que, no início dos anos 1990, levavam-se 90 minutos para sair da Isle of Dogs de carro.

Segundo Church (1990), essa crise se deveu à opção governamental pelo não planejamento. Até 1990, a LDDC não apresentara qualquer estratégia para a expansão dos transportes da antiga área portuária, apesar de já se reportarem severos problemas de deslocamento desde 1983. Não houve, por exemplo, um plano de integração de diferentes modais na região. Assim, o sistema tornou-se rapidamente deficiente trazendo custos adicionais sempre que se precisou ampliar a rede e integrar os modais.

A chegada do empreendimento Canary Wharf, cuja construção foi iniciada em 1988, com 50.000 empregos estimados, significava que investimentos em mobilidade eram necessários para torná-lo viável. Daí surgiram propostas para expandir as linhas férreas, construir uma nova linha do metrô e uma nova via de rodagem para cruzar a região, chamado Docklands Highway (Brownill, 1999). No entanto, mesmo o poder dos megaempresários da construção civil não foi suficiente para convencer o governo liberal a construir a Jubilee Line do metrô, que demandava £ 400 milhões de recursos da empreiteira para realizar a obra. Como resultado, em 1992, 45\% dos novos espaços de escritórios estavam vacantes. Paralelamente, o Canary Wharf entrou em administração judicial, tendo alugado apenas 60\% de seu espaço. Diante desse novo cenário, a LDDC passou a investir em novos arruamentos a toque de caixa, gastando cifras vultuosas para isso. A estagnação e os novos gastos levaram a própria LDDC à uma crise financeira, pois dependia dos recursos arrecadados com a venda de terras.

Em adição a esta crise, a LDDC falhava em estabelecer uma consulta aceitável às autoridades e aos grupos comunitários locais, o que consistiu em mais um fator de conflito. A Docklands Highway, por exemplo, foi apresentada como uma via de acesso local separada das demais vias já existentes, servindo apenas ao setor empresarial e, por isso, gerando muita insatisfação na população local. Como resposta, os Conselhos locais passaram a utilizar a mídia para expor as falhas da LDDC. "No final desse período, a imagem da LDDC era a de como não regenerar uma área urbana. Empresas pararam de negociar e empreendimentos falharam em se materializar, particularmente nas Royal Docks" (Brownill, 1999, p. 50).

Foi só com a saída do Canary Wharf da situação de administração judicial, em 1993, que esse empreendimento pôde contrair um empréstimo com o European Investment Bank para cobrir a contribuição demandada pelo governo para a construção da Jubilee Line do metrô. Esta se estenderia da área central de Londres na direção leste para Isle of Dogs e Stratford, dando conta de 24.000 passageiros por hora nas duas direções. A nova linha ficaria pronta apenas em 1997, arrastando por mais quatro anos a crise de mobilidade na península. No entanto, o simples início das obras do metrô e a continuidade da construção de Canary Wharf forma suficientes para tirar o mercado imobiliário local da recessão. Em 1998, 98\% das salas comerciais do empreendimento já estariam alugadas e seria iniciada a construção de dois novos 
arranha-céus além dos inicialmente planejados: um pelo Citibank e o outro pelo HSBC. Os valores das propriedades voltaram a subir e novos empreendimentos comerciais e residenciais passaram competir para se instalarem na região.

O retorno do desenvolvimento empresarial local possibilitou que fosse estabelecido o fim das operações da LDDC para 1998. Assim, a partir do início das obras do metrô, algumas mudanças começaram a ser notadas na conduta desse organismo, que passou a valorizar a relação com as representações comunitárias. "Christopher Benson, o presidente [da LDDC] de então, falava de uma 'segunda onda' de desenvolvimento, em que parte do investimento pode ser desviado para financiar ganhos sociais e comunitários" (Brownill, 1999, p. 48).

Essa nova relação com os distritos portuários possibilitaram a construção de 1.100 novas unidades residenciais, apenas do distrito de Tower Hamlets, significando 17\% de todas as construções residenciais até então. Para Brownill (1999), esse novo sucesso estava mais ligado às negociações estabelecidas com os distritos locais do que propriamente com a recuperação do mercado imobiliário. Interessada em melhorar sua imagem pública, por um lado, mas também em passar a responsabilidade sobre a manutenção de espaços públicos e dos arruamentos para as autoridades locais, a LDDC passou a financiar projetos como a construção de habitações populares e de centros comunitários. Assim, a instituição que fora criada para possibilitar a requalificação da antiga portuária a toque de caixa, passando por cima das instâncias locais de participação, passou a representar, no fim de sua vida, uma oportunidade de realização de diversos planos que tiveram origem nos fóruns populares do período do DJC (Brownill, 1999).

\section{Algumas lições aprendidas}

Os superengarrafamentos foram aspectos de grande visibilidade no que concerne às contradições do desenvolvimento laissez-faire, vindo a afetar a própria dinâmica do desenvolvimento liberal sem intervenção estatal e implicando prejuízo a muitos investidores. Foram necessários mais $£ 4$ bilhões em investimentos públicos nas Docklands para que se resolvesse a questão do transporte. Com a abertura da Jubilee Line e a construção de novos arruamentos, enfim, solucionou-se o problema, mas, até sua conclusão, passaram-se quase dez anos de estagnação, por conta dos congestionamentos. Um bom plano de transporte deveria ter sido um elemento-chave na integração da zona portuária com o restante da cidade.

Brownill e O'Hara (2015) apontam dois momentos na atuação da LDDC: o primeiro, no período Thatcher, significou uma quebra de paradigma com relação ao planejamento urbano moderno e a vigência de um novo urbanismo, avesso ao planejamento; o segundo seria o do período John Major (1989-1999), quando se afrouxou a doutrina liberal. Nessa última fase, passaram a ser aceitos um pouco de planejamento e intervenção estatal, embora ainda dentro da lógica de atração da iniciativa privada.

Para além da LDDC, em 1991, os gastos do governo na região portuária foram estimados em mais de 2,5 bilhões de libras. Esse valor se ampliou para mais de 4 bilhões em 1995 (Barnes; Colenutt; Malone, 1996), ou seja, a "mão invisível" do mercado não foi capaz de dar conta da requalificação espacial sozinha, sem ser estimulada ou subsidiada para isso. $\bigcirc$ governo interveio com verbas vultuosas numa região praticamente toda privatizada. 
Houve, portanto, no governo de Major, uma mudança de rumos. Não houve o reconhecimento formal da falha do laissez-faire em criar uma área grande de espaço corporativo, inclusive muitos dos preceitos liberais foram mantidos, mas a volta do planejamento metropolitano e da intervenção governamental se evidenciou. Tanto os investimentos em serviços públicos como as preocupações com o desenho de áreas de convívio cívico voltaram a ser temas de interesse das gestões governamentais.

Os limites à livre incorporação foram expostos. "Com 50\% do espaço de chão não ocupado nos anos 1990, a região portuária ilustrou porque os argumentos em prol de uma autoridade de planejamento metropolitanos para Londres eram agora inatacáveis" (Edwards, 1992, p. 41). A base ideológica liberal foi afrouxada e pensamentos mais balanceados passaram a prevalecer. Mesmo os empreiteiros privados estariam lembrando o governo dos benefícios de alguns aspectos do planejamento da cidade. Dentro das lições aprendidas, constatou-se que o planejamento de transportes seria uma função governamental de fundamental importância.

Apesar da recessão vivida na década de 1990, que retardou o processo de ocupação da região, Edwards (1992, p. xi) entende que as antigas docas londrinas regeneradas "deram à City e a Westminster um centro complementar de alta tecnologia que pôde permitir a Londres reter sua preeminência nos mercados financeiros mundiais". Nos anos 2000, sob o governo trabalhista de Tony Blair, já com os problemas de transporte resolvidos, a região sofreu novo boom de crescimento.

A construção de Canary Wharf foi praticamente finalizada e passou a contar com a presença de importantes empresas do setor financeiro, como CityBank, HSBC, Barclays e Credit Suisse. As grandes reformas urbanas transformaram a antiga zona portuária de um espaço discriminado e segregado da cidade numa região muitíssimo visitada e repleta de marcos turísticos. Canary Wharfé hoje um marco na paisagem e uma marca da cidade.

Embora tardio, o êxito da requalificação das Docklands londrinas e as lições aprendidas sobre a importância do planejamento fizeram com que o movimento de transformação de antigas zonas industriais e/ou pauperizadas em novas áreas gentrificadas se estendesse a todas as áreas de beira-rio situadas a leste da City of London (Davidson; Lees, 2005), reconfigurando a feição social dessa parte da cidade. Posteriormente, em 2012, os Jogos Olímpicos trouxeram o Parque Olímpico para a Stratford ao norte das Docklands, ampliando os efeitos da requalificação para todo o East End.

Muitas das críticas feitas à reforma da antiga zona portuária têm sido repetidas quanto às novas áreas de requalificação espacial - principalmente quanto ao quesito habitação social. Os prefeitos e demais responsáveis que se sucederam continuaram defendendo a lógica de que o crescimento de base liberal naturalmente se espalha socialmente e, por isso, não investem em habitação social.

No entanto, quanto ao quesito mobilidade, as autoridades administrativas de Londres compreenderam ser imprescindível realizar o planejamento de forma a se antecipar à formação de crises de mobilidade e congestionamentos e impedi-las. Por outro lado, as gestões trabalhistas compreenderam que as modalidades de planejamento de base popular têm pouco efeito se o projeto de cidade almejado não se coadunar minimamente com o interesse dos atores capazes de financiá-lo. 
Desse modo, a análise dos processos envolvidos na produção das Docklands nos leva a perceber como a práxis política interfere na concretização dos projetos e também como a consequente transformação do espaço habitado da cidade produz resultados efetivos, com efeitos políticos importantes que acabam por impor a flexibilização das doutrinas ideológicas que baseiam a ação dos diversos grupos envolvidos. Hoje as Docklands compõem uma área bastante valorizada da cidade, mas mantêm parte de sua população original por meio das Council Houses, com aluguéis subsidiados pelos conselhos locais. Por esse motivo, alguns cientistas sociais discutem a aplicabilidade do termo gentrificação (Davidson; Lees, 2005).

A antiga zona portuária não é mais uma área da cidade exclusivamente habitada pela classe trabalhadora - sua população agora é majoritariamente de classe média. No entanto, devido ao subsídio público, não houve expulsão da população mais pobre e de origem migrante. Assim, a região se tornou bastante heterogênea em termos tanto econômicos quanto sociais.

\section{Referências}

A VISION OF BRITAIN THROUGH TIME. Disponível em: http://www.visionofbritain. org. Acesso em: 26 jun. 2019.

BARNES, J.; COLENUTT, B.; MALONE, P. London: Docklands and the State. In: MALONE, P. City, capital and water. London: Routledge, 1996. p. 14-36.

BEARD, N. London Docklands: an example of inner city renewal. Geography, v. 64, n. 3 , p. 190-195, 1979. Disponível em: www.jstor.org/stable/40570212. Acesso em: 26 jun. 2019.

BROWNILL, S. Turning the East End into the West End: the lessons and legacies of the London Docklands Development Corporation. In: IMRIE, R.; THOMAS, H. (Org.). British urban policy: an evaluation of the urban development corporation, Londres: Sage, 1999. p. 43-63.

BROWNILL, S.; O'HARA, G. From planning to opportunism? Re-examining the creation of the London Docklands Development Corporation. Planning Perspectives, v. 30, n. 4, p. 537-570, 2015.

BUTLER, T. Re-urbanizing London Docklands: gentrification, suburbanization or new urbanism? International Journal of Urban and Regional Research, v. 31, n. 4, p. 759-781, 2007. Disponível em: https://onlinelibrary.wiley.com/doi/full/10.1111/j.14682427.2007.00758.x. Acesso em: 26 jun. 2019.

$\mathrm{CHURCH}, \mathrm{A}$. Transport and urban regeneration in London Docklands: a victim of success or a failure to plan? Cities, v. 7, n. 4, p. 289-303, 1990. Disponível em: https://www. sciencedirect.com/science/article/pii/0264275190900275. Acesso em: 26 jun. 2019.

DAVIDSON, M.; LEES, L. New-build "gentrification" and London's riverside renaissance, Environment and Planning, v. 37, n. 7, p. 1165-1190, 2005. Disponível em: https:// journals.sagepub.com/doi/10.1068/a3739. Acesso em: 26 jun. 2019. 
DUARTE, R. G. O processo de reabilitação e renovação urbana na cidade do Rio De Janeiro e suas perspectivas. Scripta Nova - Revista Electrónica de Geografía Y Ciencias Sociales, v. IX, n. 194, p. 44, 2005. Disponível em: http://www.ub.edu/geocrit/sn/sn194-44.htm. Acesso em: 26 jun. 2019.

EDWARDS, B. London Docklands: urban design in an age of deregulation. Oxford: Butterworth-Heinemann, 1992.

HINSLEY, H.; MALONE, P. London: planning and design in Docklands. In: MALONE, P. City, capital and water. Londres: Routledge, 1996. p. 37-64.

KOLLEWE, J. Canary Wharf timeline: from the Thatcher years to Qatari control. The Guardian, 28 jan. 2015. Disponível em: https://www.theguardian.com/business/2015/ jan/28/canary-wharf-timeline-london-building-docklands-thatcher. Acesso em: 26 jun. 2019 .

LOVELL, J. Stevedores and dockers: a study of trade unionism in the Port of London, 1870-1914. London: Palgrave Macmillan, 1969.

MOGG, E. London in miniature: surroundings and villages. London, 1806. Disponível em: https://commons.wikimedia.org/wiki/File:1806_Mogg_Pocket_or_Case_Map_of_ London,_England_-_Geographicus_-_London-mogg-1806.jpg/. Acesso em: 17 abr. 2019 .

MONIÉ, F.; VIDAL, S. M. S. C. Cidades, portos e cidades portuárias na era da integração produtiva. Revista de Administração Pública, v. 40, n. 6, p. 975-995, 2006. Disponível em: http://www.scielo.br/scielo.php?pid=S0034-76122006000600003Escript=sci_ abstractEtlng=pt. Acesso em: 26 jun. 2019.

PAGE, S. The London Docklands: redevelopment schemes in the 1980s. Geography, v. 72, n. 1, p. 59-63, 1987. Disponível em: http://www.jstor.org/stable/40571222. Acesso em: 26 jun. 2019.

PORT OF LONDON AUTHORITY. History of the Port of London pre 1908. Disponível em: http://www.pla.co.uk/Port-Trade/History-of-the-Port-of-London-pre-1908. Acesso em: 26 jun. 2019.

SCHUBERT, D. Transformation processes on waterfronts in seaport cities: causes and trends between divergence and convergence. In: KOKOT, W.; GANDELSMAN-TRIER, M.; WILDNER, K.; WONNEBERGER, A. (Org.). Port cities as areas of transition: ethnographic perspectives. Bielefeld: Transcript, 2008. p. 25-46. Disponível em: https:// www.degruyter.com/viewbooktoc/product/467457. Acesso em: 26 jun. 2019.

SCOTT, S. The Thames and the Tower of London Supposedly on the King's Birthday. 1771. 1 fotografia colorida. Arquivo original: 6,398 × 3,274 pixels; dimensões: 4,08 MB. Disponível em: https://commons.wikimedia.org/wiki/File:Samuel_Scott_-_The_Thames_and_the_Tower_of_London_Supposedly_on_the_King\% 27 s_Birthday_-_Google_Art_Project.jpg. Acesso em: 17 abr. 2019. 
SMITH, N. Toward a theory of gentrification: a back to the city movement by capital, not people. Journal of the American Planning Association, v. 45, n. 4, p. 538-548, 1979. Disponível em: https://www.tandfonline.com/doi/pdf/10.1080/01944367908977002? needAccess=true. Acesso em: 26 jun. 2019.

WARD, R. London: the emerging docklands city. Built Environment, v. 12, n. 3, p. 117-127, 1986.

WELLER, E. River Thames with the Docks from Woolwich to the Tower, 1882. 1884. 1 mapa colorido. Arquivo original: 4,499 × 1,217 pixels; dimensões: $982 \mathrm{~KB}$. Disponível em: https://commons.wikimedia.org/wiki/File:Thames_river_1882.jpg. Acesso em: 26 jun. 2019.

YOUSAF, A. Canary Wharf after sunset. 2014. 1 fotografia colorida. Arquivo original: 5,520 × 3,680 pixels; dimensões: 4,54 MB. Disponível em: https://commons.wikimedia.org/wiki/File:Canary_Wharf_after_sunset_(14950863732).jpg. Acesso em: 17 abr. 2019. 